\title{
The First Record of Zoonotic Genes of Cutaneous Leishmaniasis among Human, Dogs, and Sandflies by Nested Polymerase Chain Reaction and Phylogenetic Analyses
}

\author{
Rasha Alsaad $^{1,2 *}$ (D), May Hameed ${ }^{2}$ (D) \\ ${ }^{1}$ Department of Microbiology, University of Misan, Faculty of Medicine, Misan, Iraq; ${ }^{2}$ Department of Parasitology, University of \\ Baghdad, College of Veterinary Medicine, Baghdad, Iraq
}

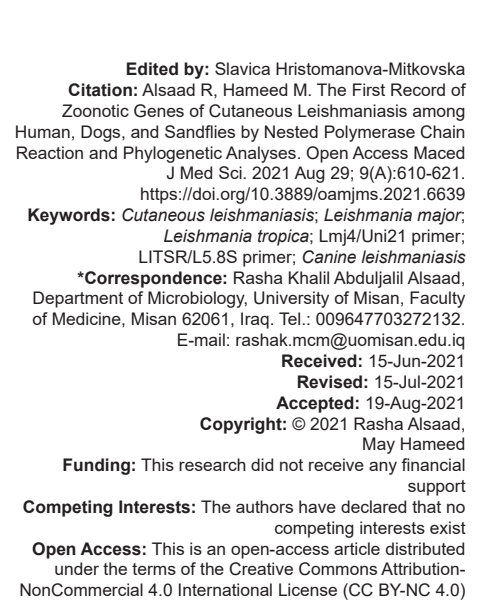

\begin{abstract}
BACKGROUND: Cutaneous leishmaniasis $(\mathrm{CL})$ is one of the zoonotic diseases that is caused by protozoa of the genus Leishmania.

AIM: The study aimed to diagnosed CL in human, dogs, and sandflies by PCR, and identification the zoonotic gene of $C L$ by the nested PCR technique.

METHODS: A total of 100 patients with CL, 237 of owned-dogs, and 147 females' sandflies collected.

RESULTS: Approximately, $88 \%$ of human samples, $95.77 \%$ skin biopsies and $20.69 \%$ of blood samples of dogs, and $40.58 \%$ of sandflies tissues were positive for $\mathrm{L}$. major, while L. tropica infection was positive in $12 \%$ of human in $4.23 \%$ symptomatic, and $6.89 \%$ asymptomatic of dogs, and in $27.54 \%$ of sandflies samples. The sequence ID of the local L. major in human were registered in NCBI as (MW421598.1, MW421599.1, MW421600.1), in dogs (MW421601.1, MW421602.1, MW421603.1), and sandflies (MW421604.1, MW421605.1, MW421606.1). While L. tropica in human were registered in NCBI as (MW421604.1, MW421605.1, MW421606.1), in dogs (MW421428.1, MW421429.1), and in sandflies (MW421430.1, MW421431.1)
\end{abstract}

CONCLUSION: To our knowledge, this is the first study that contributes to the diagnosis of CL spp. in three different hosts (human, dogs, and sandflies) at the same time, particularly in Iraq and in Middle East countries.

\section{Introduction}

Leishmaniasis is one of the major vector-borne communicable diseases in the world. It is a zoonotic infection that is caused by obligate intracellular protozoa and hemoflagellate of the genus Leishmania [1], [2], [3], [4], [5]. Old World cutaneous leishmaniasis (CL) caused by Leishmania tropica, and a rural or wet type caused by Leishmania major [6]. Epidemiological studies in the Middle East have shown that anthroponotic CL caused by $L$. tropica and zoonotic CL caused by $L$. major in Saudi Arabia, Iraq, Iran, Afghanistan, Pakistan, and Yemen [7], [8]. It is endemic in Iraq, where both forms of the disease, cutaneous and visceral, are found [9]. Natural transmission of Leishmania parasites is carried out by sandflies of the genus Phlebotomus (Old World) [4]. Phlebotomine sandflies are responsible for the transmission of several human diseases, including bartonellosis, leishmaniasis, and sandfly fever viruses [10]. L. major-infected dogs have been reported in Saudi Arabia and Egypt, as are potential primary reservoirs host infected by sand flies [11], [12].
Recently, CL has increased and extensively spreading to new geographical zones as documented in neighboring countries. This unexpected rise of the patient's number in endemic regions is multifactorial and attributed to population movements and crowding, ecological disturbances, changing patterns of international trade and traveling, political unrest, natural disasters, and drug resistance of parasites [13].

For many years ago, several polymerase chain reaction (PCR)-based approaches have been employed for typing Leishmania spp. Multilocus Enzyme Electrophoresis is considered the gold standard for Leishmania identification [14]. DNA sequencing, PCR-restriction fragment length polymorphism (RFLP) [15], Nested PCR [16], and Multilocus Sequence Typing [17], [18] have all been employed for these objectives.

This work aimed to explore molecular properties and phylogenetic analyses by evaluating popular markers in SSU (18S) rRNA gene, from clinical samples with nested PCR and sequencing in Iraq. Moreover, this study is unique, and generally to 
our knowledge, it is the first study conducting on three different hosts of Leishmania which differs from the studies previously performed in the regions concerning phylogenetic analyses of CL in Middle East countries.

\section{Materials and Methods}

\section{Ethical consideration}

The Medical Ethical Committee at the College of Veterinary Medicine, University of Baghdad approved this study (Ref. No. 2650, 17/12/2019). Written informed consent was obtained from each participant and personal data were kept confidential.

\section{Patients}

A total of 100 patients with $C L$ were enrolled in this study. They attended the Dermatological and Venereology Department in Al-Sadder Teaching Hospital and public health laboratories in Misan Health Directorate, Misan Province, Iraq.

\section{Dogs}

A total of 237 (blood and skin lesions) from dogs were collected from patients with $C L$ when visiting their homes of both sex and maturity. There were 74 dogs with clinical signs of CL, whiereas 163 were asymptomatic. The examination done by us, since we are veterinarian graduated from College of Medicine.

\section{Pus and discharge aspiration}

Each skin lesion was cleaned with iodine or ethanol, and then about 0.5 to $1 \mathrm{ml}$ of Lock's solution was subcutaneously injected using a disposable insulin syringe at the peripheral edges of the lesion. The solutions were stored in Eppendorf tubes to be directly used for examination by direct smear and culture.

\section{Swab collection}

Some patients presented with ulcerative or cystic lesions and were eligible for applying a swab to collect pus or any discharge materials from the lesions. A cotton swab was used to swab overall lesion area and then placed in sample tubes containing $500 \mathrm{ml}$ of phosphate-buffered saline solution.

\section{Filter paper collection}

Skin lesions were cleaned with $70 \%$ alcohol, and filter papers were gently touched on the lesion around the edges of the cuts and allowed to air dry thoroughly.

\section{Blood samples collection}

Blood samples from domestic dogs were collected. A sample of 2-5 $\mathrm{ml}$ was taken from the cephalic vein of each dog into EDTA tubes and transported to the laboratory.

\section{Skin scraping}

A blunt blade scrape in the direction of hair growth was used. Initially, we scraped the superficial layer and then subsequently deeply (enough to cause capillary ooze). Then, the scraped small pieces were transferred to a cup contain BPS $(5 \mathrm{ml})$ and stored at $-20^{\circ} \mathrm{C}$ before DNA isolation [32].

\section{Sandflies}

A total of 268 sandflies (engorged with blood from human and dogs) were collected from different areas near patients' homes in Misan province including indoors, outdoors, rat burrows, stables, residential clay houses, fields, and the edges of rivers. Light traps and sticky oil paper (insect glue snares) were used to collect whole insects; these were then put in cups containing sterile normal saline or petri dishes for examination and diagnosis. Identification and differentiation of sandflies from other insects depends on their shape, morphology, and size, according to Habeeb [10].

\section{PCR}

Molecular diagnosis depending on the three types of primers, which were $1^{\text {st }}$ primer LEI-1 (Forward) and LEI-2 (Reverse) to diagnosed Leishmania spp.; $2^{\text {nd }}$ primer LITSR (Forward) and L5.8S (Reverse) for genotyping of $L$. major; and $3^{\text {rd }}$ primer Lmj4 (Forward) and Uni21 (Reverse) for genotyping of $L$. tropica. In addition, the SSU (18S) rRNA gene was amplified in a nested PCR reaction.

\section{DNA extraction and purification}

Genomic DNA was extracted from 100 human, 237 (74 biopsy, and 163 blood) dogs, and 147 female sandflies, diagnosed with CL using (MagPurix ${ }^{\circledR}$ Viral/ Pathogen Nucleic Acids Extraction Kit A/Zinexts Life Science Corp./Taiwan).

\section{Agarose gel electrophoresis}

DNA was visualized by $(1 \%)$ agarose gel electrophoresis and stained with GelStain-GREEN (V2), according to Sambrook and Russell [19]. 


\section{DNA concentration and purity measurement}

All eluted DNA samples were measured using Nano-drop, by taking $0.5 \mu \mathrm{l}$ of each eluted DNA sample using a micropipette, putting it in a well, closing the apparatus, then measuring the concentration of the eluted DNA. All concentrations were recorded in a Microsoft Excel 2010 spreadsheet labeled for each sample.

\section{Primers preparation}

The primers were supplied by Alpha-DNA Company (Canada) as lyophilized products of 100 picomole concentrations. Alpha-DNA's company protocol was adopted for primer use, by bringing the final concentration of the primers to $10 \mathrm{pmol} / \mathrm{\mu l}$ in nuclease-free water. The lyophilized primer was dissolved in $1 \mathrm{ml}$ nuclease-free water and stored at $-20^{\circ} \mathrm{C}$. To avoid repeated freezing and thawing, small aliquots were prepared at suitable concentrations and stored at $-20^{\circ} \mathrm{C}$ until use. The primers' names, sequences, and products size listed in Table 1.

\begin{tabular}{|c|c|c|}
\hline Primers & Sequence & Size (bp) \\
\hline \multicolumn{3}{|c|}{$\begin{array}{l}\text { SSU (18S) rRNA } \\
F\end{array}$} \\
\hline$R^{\text {LEI-1 }}$ & 5'-GGT TCC TTT CCT GAT TTA CG-3' & 650 \\
\hline $\mathrm{F}^{\mathrm{LEI}-2}$ & 5'-GGC CGG TAAAGG CCG AAT AG-3' & \\
\hline$R^{\text {LITSR }}$ & 5'-CTG GAT CAT TTT CCG ATG-3' & $302-338$ \\
\hline$F^{L 5.8 S}$ & 5'-TGA TAC CAC TTA TCG CAC TT-3' & \\
\hline Lmj4 & 5'-CTA GTT TCC CGC CTC CGA G-3' & 600 \\
\hline
\end{tabular}

\section{PCR amplification of SSU (18S) rRNA gene}

Genomic DNA was amplified using the general primers LEI-1 (Forward) and LEI-2 (Reverse) for detection of Leishmania spp. and used to produce a 650 bp product. The lyophilized blue pellet was dissolved by vortexing and briefly spun down. Then, PCR was performed on the samples. After that, samples were loaded on agarose gel without adding a loading-dye mixture, and electrophoresis was performed. The PCR tubes were transferred to a preheated thermocycler, and the program was started as following steps: i. initial denaturation (at $96^{\circ} \mathrm{C}$ for $900 \mathrm{~s}$ ), ii. annealing (at $60^{\circ} \mathrm{C}$ for $20 \mathrm{~s}$ in 40 cycles), and iii. final extension (at $72^{\circ} \mathrm{C}$ for $300 \mathrm{~s}$ in one cycle). A $5 \mu$ sample of PCR product was added to each well of agarose gel. The molecular weight of PCR amplified product was determined according to 2000-100 bp ladder after $60 \mathrm{~min}$ at $70 \mathrm{~V}$.

\section{Nested PCR http://www.pcrstation.com/ nestedpcr/2020}

Detection of L. major

The PCR mix for the nested reaction consisted of new master mix tubes with the addition of the following:
Forward primer (LITSR) $(2.0 \mu \mathrm{l})$, reverse primer (L5.8S) $(2.0 \mu \mathrm{l}), 1^{\text {st }} \mathrm{PCR}$ product $(5.0 \mu \mathrm{l})$, and nuclease free water $(11.0 \mu \mathrm{l})$. As the previous protocol of amplificated PCR, tubes were transferred to preheated thermocycler and started the program, as following steps: i. Initial Denaturation (at $95^{\circ} \mathrm{C}$ for $300 \mathrm{~s}$ ), ii. annealing (at $65^{\circ} \mathrm{C}$ for $40 \mathrm{~s}$ in 40 cycles), iii. final extension (at $72^{\circ} \mathrm{C}$ for $5 \mathrm{~s}$ in one cycle). The detection of the nested PCR amplified product of 302-338 bp was achieved by electrophoresis, as with the primary PCR.

\section{Detection of L. tropica}

The PCR mix for the nested reaction consisted of a new master mix tube with the addition of the following: Forward primer (Lmj4) $(2.0 \mu \mathrm{l})$, reverse primer (Uni21) $(2.0 \mu \mathrm{l}), 1^{\text {st }} \mathrm{PCR}$ product $(5.0 \mu \mathrm{l})$, and nuclease free water $(11.0 \mu \mathrm{l})$. As with the previous protocol for PCR amplification, tubes were transferred to a preheated thermocycler, and the program was started, as following: i. Initial denaturation (at $95^{\circ} \mathrm{C}$ for $900 \mathrm{~s}$ ), ii. Annealing (at $60^{\circ} \mathrm{C}$ for $20 \mathrm{~s}$ in 40 cycles), iii. Final extension (at $72^{\circ} \mathrm{C}$ for $300 \mathrm{~s}$ in one cycle). The detection of the nested PCR amplified product of $600 \mathrm{bp}$ was achieved by electrophoresis, as with the primary PCR.

\section{Sequence and phylogenetic analysis}

The sequencing analysis of the desired gene as a method of choice for use in epidemiological, clinical, genetic, and taxonomic studies, and also for the management of CL patients with unknown origins, is highly emphasized [20], [21]. The L. major LITSR gene and L. tropica Lmj4 gene were registered after correspondence with the National Center for Biotechnology Information; accession numbers were obtained and became a reference for Iraq, the Middle East, and the world. A total of 15 sequence samples (three each for human, dogs, and sandflies for L. major, two each for human, dogs, and sandflies for L. tropica) were sent to the Macrogen Company, the Genomic Medicine Institute of the Seoul National University College of Medicine, Korea. Hence, all samples were analyzed by National Center for Biotechnology Information (NCBI-BLAST).

\section{Statistical analysis}

All data collected were entered for statistical analysis into the Statistical Package for the Social Sciences version 24 (SPSS v24) (SPSS Inc., Chicago, Illinois, USA). Differences between infection rates were described by Chi-square $(\chi 2)$ for Fishers' exact test. A $p<0.05$ was considered statistically significant. 


\section{Results}

\section{DNA extraction}

Genomic DNAwas extracted from samples from 100 patients (skin biopsies), 237 dog samples (74 skin biopsies and 163 blood samples), and 147 samples from female sandflies (tissue samples). DNA extraction and purification were successfully performed using Isolation Kit (MagPurix ${ }^{\circledR}$ Viral/Pathogen Nucleic Acids Extraction Kit A/Zinexts Life Science Corp./Taiwan). All samples contained whole eluted DNA, as shown in Figure 1. Each eluted DNA sample was measured using nanodrop.

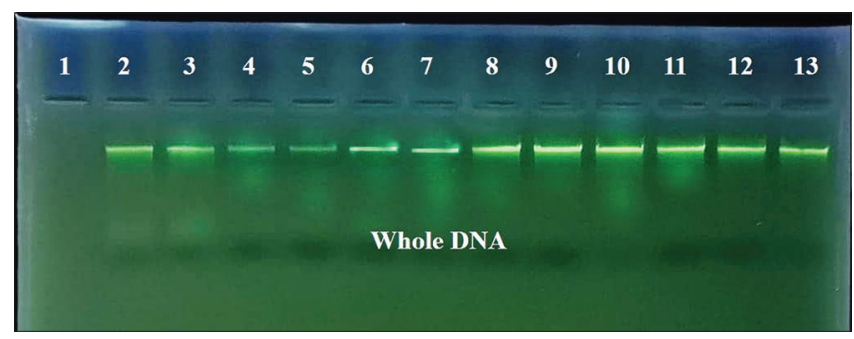

Figure 1: Gel electrophoresis of genomic DNA extracted from samples in $1 \%$ agarose gel at $70 \mathrm{~V} / \mathrm{cm}^{2}$ for $30 \mathrm{~min}$. DNA was visualized under U.V. light after staining with GelStain-GREEN (V2)

\section{genes}

\section{PCR amplification of SSU (18S) rRNA}

The genomic DNA was amplified using the general primers LEl-1 (Forward) and LEI-2 (Reverse) to detect Leishmania spp., which were used to produce a 650bp sequence. Product primers for the first amplification used 100 human skin biopsy samples, 74 skin biopsies and 163 blood samples from dogs, and 147 female's sandfly tissue samples.

The findings showed that all human samples (100, 100\%), 71 (95.95\%) skin biopsies from dogs, $58(35.58 \%)$ blood samples from dogs, and 69 (46.94\%) female sandfly tissues were positive for Leishmania spp., with a high statistically significant difference $(p<0.01)$, as shown in Table 2 and Figure 2.

Table 2: Results of molecular diagnosis of the initial PCR

\begin{tabular}{|c|c|c|c|c|c|}
\hline Host & No. of samples & $\begin{array}{l}\text { Positive for initial } \\
\text { PCR Leishmania spp. }\end{array}$ & $\%$ & $\begin{array}{l}\text { Negative for initial } \\
\text { PCR Leishmania spp. }\end{array}$ & $\%$ \\
\hline $\begin{array}{l}\text { Human } \\
\text { Dogs }\end{array}$ & 100 & 100 & 100 & 0 & 0 \\
\hline Biopsies & 74 & 71 & 95.95 & 3 & 4.05 \\
\hline Blood & 163 & 58 & 35.58 & 105 & 64.42 \\
\hline Sandflies & 147 & 69 & 46.94 & 78 & 53.06 \\
\hline
\end{tabular}

All positive PCR products based on the initial primers were examined in the next step using secondary primers for the amplification of nested PCR (LITSR, which generated a 302-338 bp sequence), used to diagnose $L$. major. The results revealed $88(88 \%)$ human biopsies, 68 (95.77\%) skin biopsies from dogs, $12(20.69 \%)$ blood samples from dogs, and $28(40.58 \%)$ females sandfly tissues were positive to

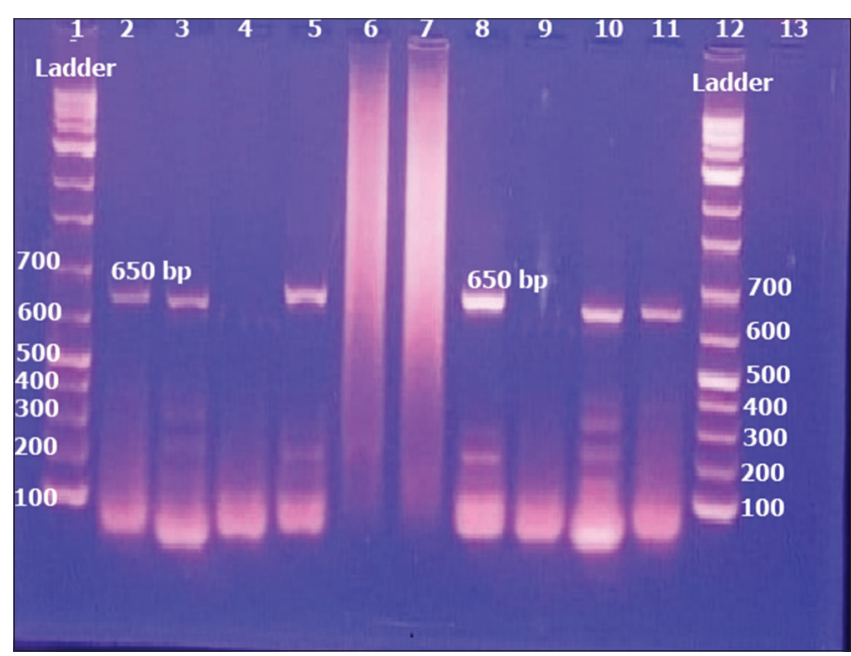

Figure 2: Gel electrophoresis of amplified DNA from Leishmania spp. by using the primer set LEI-1 and LEI-2 primers of SSU (18S) rRNA. Lane 0: DNA ladder. Lane 1, 3: Human DNA positive to $650 \mathrm{bp}$. Lane 4, 5: Dog DNA positive to $650 \mathrm{bp}$. Lane 6: Sandfly DNA positive to 650 bp. Lane 2: Water

L. major, with a high statistically significant difference $(p<0.01)$, as shown in Table 3 and Figure 3.

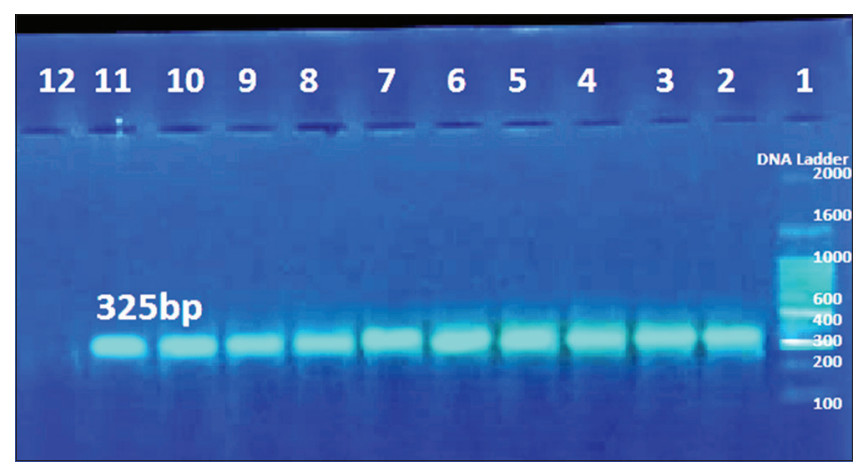

Figure 3: Gel electrophoresis of amplified DNA from Leishmania major using primer set LITSR and L5.8S primers of SSU (18S) rRNA. Lane 1: DNA ladder. Lane 2, 3, 4, 5: Human DNA positive to 302-338 bp. Lane 6, 7, 8, 9: Dog DNA positive to 302-338 bp. Lane 10, 11: sandfly DNA positive to 302-338 bp. Lane 12: Water

The negative PCR products using secondary primers were then examined using the third set of primers for the amplification of nested PCR (Lmj4, which generated a 600 bp sequence), used to diagnosed L. tropica. The results showed that $12(12 \%)$ human biopsies, $3(4.23 \%)$ dog skin biopsies, 4 (6.89\%) dog blood samples, and $19(27.54 \%)$ females sandfly tissue samples were positive to $L$. tropica, with a high statistically significant difference $(p<0.01)$, as shown in Table 3, and Figure 4.

\section{LITSR gene \\ Sequencing and phylogenetic analyses for}

Sequencing of the LITSR gene was used DNA extracted from three lesions each from human, dogs, and sandflies) and was performed using phylogenetic tree analysis and compared with NCBI-BLAST L. major. The types of substitutions, locations, and nucleotides in all samples are shown in Table 4. 
Table 3: Results of molecular diagnosis: Nested PCR (positive for secondary PCR Leishmania major) and (positive for third PCR Leishmania tropica)

\begin{tabular}{|c|c|c|c|c|c|c|c|}
\hline Host & $\begin{array}{l}\text { No. of samples } \\
\text { infected with L. spp. }\end{array}$ & $\begin{array}{l}\text { Positive for secondary } \\
\text { PCR Leishmania major }\end{array}$ & $\%$ & $\begin{array}{l}\text { Positive for } 3^{\text {rd }} \mathrm{PCR} \\
\text { Leishmania tropica }\end{array}$ & $\%$ & $\begin{array}{l}\text { Negative for } 2^{\text {nd }} \\
\text { and } 3^{\text {rd }} \text { PCR }\end{array}$ & $\%$ \\
\hline Human & 100 & 88 & 88 & 12 & 12 & - & - \\
\hline Dogs & & & & & & & - \\
\hline Biopsies & 71 & 68 & 95.77 & 3 & 4.23 & - & \\
\hline Blood & 58 & 12 & 20.69 & 4 & 6.89 & 42 & \\
\hline \multirow[t]{2}{*}{ Sandflies } & 69 & 28 & 40.58 & 19 & 27.54 & 50 & 72.46 \\
\hline & & \multicolumn{2}{|c|}{ Chi-square $\left(x^{2}\right)=13.78, p<0.01$} & \multicolumn{3}{|c|}{ Chi-square $\left(x^{2}\right)=17.92, p<0.01$} & \\
\hline
\end{tabular}

PCR: Polymerase chain reaction

Table 4: Type of polymorphism of Leishmania major of LITSR gene

\begin{tabular}{|c|c|c|c|c|c|c|}
\hline S. No. & Type of substitution & Location & Nucleotide & Sequence ID with compare & Sequence ID with submission & Identities (\%) \\
\hline \multirow[t]{2}{*}{1} & Transition & 56 & GIA & MN604128.1 & MW421598.1 & 99 \\
\hline & Transition & 69 & AlG & & & \\
\hline \multirow[t]{3}{*}{2} & Transition & 69 & AlG & MN604128.1 & MW421599.1 & 99 \\
\hline & Transversion & 75 & AIT & & & \\
\hline & Transition & 118 & AIG & & & \\
\hline \multirow[t]{3}{*}{3} & Transition & 69 & AIG & MN604128.1 & MW421600.1 & 99 \\
\hline & Transition & 139 & AIG & & & \\
\hline & Transversion & 141 & $\mathrm{ClG}$ & & & \\
\hline \multirow[t]{3}{*}{4} & Transversion or Transition & 193 & $N(A, C, G, T) \backslash A$ & KU949582.1 & MW421601.1 & 99 \\
\hline & Transversion or Transition & 195 & $N(A, C, G, T) \backslash G$ & & & \\
\hline & Transversion or Transition & 197 & $N(A, C, G, T) \backslash G$ & & & \\
\hline \multirow[t]{4}{*}{5} & Transversion & 151 & AIT & KU949582.1 & MW421602.1 & 99 \\
\hline & Transversion or Transition & 193 & $N(A, C, G, T) \backslash A$ & & & \\
\hline & Transversion or Transition & 195 & $N(A, C, G, T) \backslash G$ & & & \\
\hline & Transversion or Transition & 197 & $N(A, C, G, T) \backslash G$ & & & \\
\hline \multirow[t]{4}{*}{6} & Transversion or Transition & 193 & $N(A, C, G, T) \backslash A$ & KU949582.1 & MW421603.1 & 99 \\
\hline & Transversion or Transition & 195 & $N(A, C, G, T) \backslash G$ & & & \\
\hline & Transversion or Transition & 197 & $N(A, C, G, T) \backslash G$ & & & \\
\hline & Transition & 225 & CIT & & & \\
\hline 7 & Transition & 264 & $T \backslash C$ & KC880116.1 & MW421604.1 & 99 \\
\hline \multirow[t]{2}{*}{8} & Transition & 242 & GVA & KC880116.1 & MW421605.1 & 99 \\
\hline & Transition & 264 & TIC & & & \\
\hline \multirow[t]{2}{*}{9} & Transition & 248 & $\mathrm{TIC}$ & KC880116.1 & MW421606.1 & 99 \\
\hline & Transition & 264 & $\mathrm{~T} \backslash \mathrm{C}$ & & & \\
\hline
\end{tabular}

Our sequence IDs of the local L. major in human, samples No.1, No.2, and No.3 are (MW421598.1, MW421599.1, and MW421600.1), recorded in NCBIBLAST L. major. They are closely related, at $99 \%$, to MN604128.1 in Jordan, MH347921.1 in Turkey: Sanliurfa, KY882278.1 in Iraq: Sulaimani, MF522259.1 in Iran, KF612022.1 in Thailand, KP874100.1 in Iran: Mashhad, HG512909.1 in Belgium, MW053321.1 in

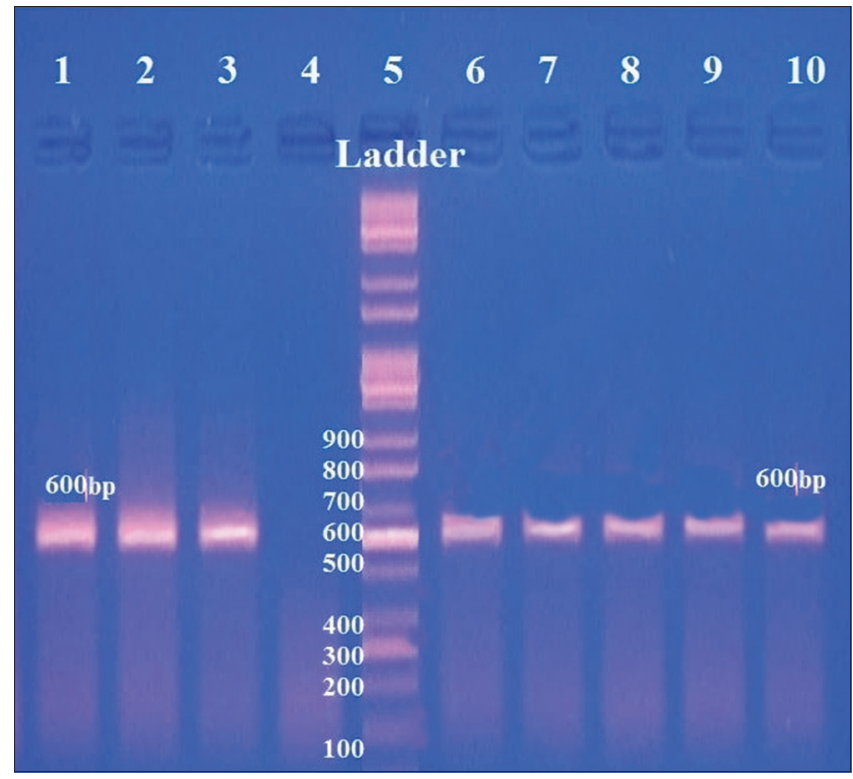

Figure 4: Gel electrophoresis of amplified DNA from Leishmania tropica using primer set Lmj4 and Uni21 primers of SSU (18S) rRNA. Lane 5: DNA ladder. Lane 1, 2, 3: Human DNA positive to $600 \mathrm{bp}$. Lane 6, 7, 8: Dog DNA positive to 600 bp. Lane 9, 10: Sandfly DNA positive to $600 \mathrm{bp}$. Lane 4: Water
India: West Bengal, FR796423.1 in United Kingdom, FJ753394.1 in USA, AY550178.1 in Germany, AJ300482.1 in Kenya, KX821679.1 in Austria, and AJ300481.1 in Sudan.

The sequence IDs of the local L. major in dogs, samples No.4, No.5, and No.6, are MW421601.1, MW421602.1, MW421603.1, recorded in NCBIBLAST L. major in dogs, which are closely related to EF413075.1 in Iran, KU949582.1 in Mediterranean Sea, and KU949581.1 in Mediterranean Sea, at 99\%.

The sequence IDs of the local L. major samples in sandflies, No.7, No.8, and No.9 are MW421604.1, MW421605.1, MW421606.1, registered in NCBI-BLAST. L. major in sandflies is closely related to KC880116.1 in Iran: llam province, KC880115.1 in Iran: Ilam province, KC880114.1 in Iran: Ilam province, KC880113.1 in Iran: Ilam province, KC880112.1 in Iran: Ilam province, at $99 \%$, and with MT966015.1 in West Bank, EF413078.1 in Iran, EF413077.1 in Iran at 98\%, as shown in Tables 4 and 5, and Figure 5.

\section{Lmj4 gene \\ Sequencing and phylogenetic analyses for}

Sequencing of the Lmj4 gene used DNA extracted from two lesions from each of human, dogs, and sandflies and was performed using phylogenetic tree analysis and compared with NCBI-BLAST $L$. tropica. The types of substitutions, locations, and nucleotides for all samples are shown in Table 6. 


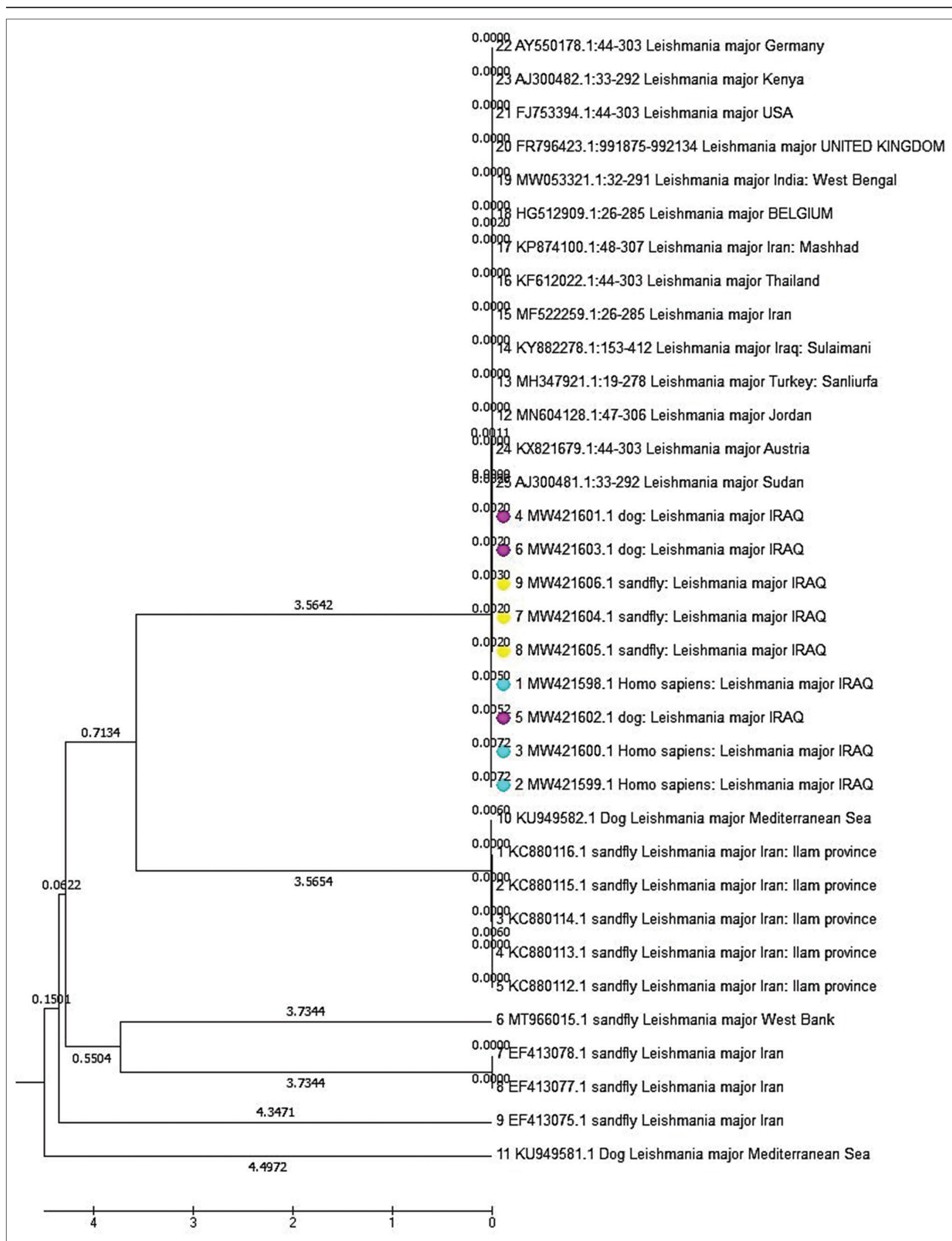

Figure 5: Neighbor-joining tree Leishmania major of LITSR gene. New sequences derived from this study are marked with blue for human, red for dogs, and yellow for sandflies. The GenBank accession numbers, species of infected host, and country of origin are included for each sequence 
Table 5: Type of polymorphism of Leishmania major of LITSR gene

\begin{tabular}{|c|c|c|c|c|c|}
\hline $\begin{array}{l}\text { S. } \\
\text { No }\end{array}$ & Accession No. & Country & Source & Host & $\begin{array}{l}\text { Compatibility } \\
(\%)\end{array}$ \\
\hline 1. & KC880116.1 & $\begin{array}{l}\text { Iran: Ilam } \\
\text { province }\end{array}$ & Leishmania major & Sandfly & 99 \\
\hline 2. & KC880115.1 & $\begin{array}{l}\text { Iran: Ilam } \\
\text { province }\end{array}$ & Leishmania major & Sandfly & 99 \\
\hline 3. & KC880114.1 & $\begin{array}{l}\text { Iran: Ilam } \\
\text { province }\end{array}$ & Leishmania major & Sandfly & 99 \\
\hline 4. & KC880113.1 & $\begin{array}{l}\text { Iran: Ilam } \\
\text { province }\end{array}$ & Leishmania major & Sandfly & 99 \\
\hline 5. & KC880112.1 & $\begin{array}{l}\text { Iran: Ilam } \\
\text { province }\end{array}$ & Leishmania major & Sandfly & 99 \\
\hline 6. & MT966015.1 & West Bank & Leishmania major & Sandfly & 98 \\
\hline 7. & EF413078.1 & Iran & Leishmania major & Sandfly & 98 \\
\hline 8. & EF413077.1 & Iran & Leishmania major & Sandfly & 98 \\
\hline 9. & EF413075.1 & Iran & Leishmania major & Dog & 98 \\
\hline 10. & KU949582.1 & $\begin{array}{l}\text { Mediterranean } \\
\text { Sea }\end{array}$ & Leishmania major & Dog & 99 \\
\hline 11. & KU949581.1 & $\begin{array}{l}\text { Mediterranean } \\
\text { Sea }\end{array}$ & Leishmania major & Dog & 99 \\
\hline 12. & MN604128.1 & Jordan & Leishmania major & Homo sapiens & 99 \\
\hline 13. & MH347921.1 & Turkey: Sanliurfa & Leishmania major & Homo sapiens & 99 \\
\hline 14. & KY882278.1 & Iraq: Sulaimani & Leishmania major & Homo sapiens & 99 \\
\hline 15. & MF522259.1 & Iran & Leishmania major & Homo sapiens & 99 \\
\hline 16. & KF612022.1 & Thailand & Leishmania major & Homo sapiens & 99 \\
\hline 17. & KP874100.1 & Iran: Mashhad & Leishmania major & Homo sapiens & 99 \\
\hline 18. & HG512909.1 & Belgium & Leishmania major & Homo sapiens & 99 \\
\hline 19. & MW053321.1 & $\begin{array}{l}\text { India: West } \\
\text { Bengal }\end{array}$ & Leishmania major & Homo sapiens & 99 \\
\hline 20. & FR796423.1 & United Kingdom & Leishmania major & Homo sapiens & 99 \\
\hline 21. & FJ753394.1 & USA & Leishmania major & Homo sapiens & 99 \\
\hline 22. & AY550178.1 & Germany & Leishmania major & Homo sapiens & 99 \\
\hline 23. & AJ300482.1 & Kenya & Leishmania major & Homo sapiens & 99 \\
\hline 24. & KX821679.1 & Austria & Leishmania major & Homo sapiens & 99 \\
\hline 25. & AJ300481.1 & Sudan & Leishmania major & Homo sapiens & 99 \\
\hline
\end{tabular}

In human, the sequence IDs of the local L. tropica samples No.1 and No.2 are MW421426.1 and MW421427.1, registered in NCBI-BLAST L. tropica. They are closely related to Z32843.1 in Russia and MH511158.1 in Iraq: Kute, at 99\%.

Among dogs, the sequence IDs of the local L. tropica samples No.3 and No.4 are MW421428.1 and MW421429.1, recorded in NCBI-BLAST L. tropica. They are closely related to Z32843.1 in Russia, at $99 \%$.

Table 6: Type of polymorphism of Leishmania tropica of Lmj4 gene

\begin{tabular}{|c|c|c|c|c|c|c|}
\hline $\begin{array}{l}\text { No. of } \\
\text { sample }\end{array}$ & $\begin{array}{l}\text { Type of } \\
\text { substitution }\end{array}$ & Location & Nucleotide & $\begin{array}{l}\text { Sequence ID } \\
\text { with compare }\end{array}$ & $\begin{array}{l}\text { Sequence ID } \\
\text { with submission }\end{array}$ & $\begin{array}{l}\text { Identity } \\
(\%)\end{array}$ \\
\hline 1 & Transversion & 118 & $T \backslash G$ & Z32843.1 & MW421426.1 & 99 \\
\hline 2 & Transition & 189 & $T \backslash C$ & Z32843.1 & MW421427.1 & 99 \\
\hline 3 & Transversion & 520 & CIG & Z32843.1 & MW421428.1 & 99 \\
\hline \multirow[t]{3}{*}{4} & Transition & 274 & $T \backslash C$ & Z32843.1 & MW421429.1 & 99 \\
\hline & Transition & 463 & AIG & & & \\
\hline & Transition & 464 & AlG & & & \\
\hline 5 & Transversion & 208 & AlT & Z32843.1 & MW421430.1 & 99 \\
\hline \multirow[t]{2}{*}{6} & Transversion & 208 & AIT & Z32843.1 & MW421431.1 & 99 \\
\hline & Transition & 307 & AlG & & & \\
\hline
\end{tabular}

In sandflies, the sequence IDs of the local L. tropica samples No.5 and No.6 are MW421430.1 and MW421431.1, recorded in NCBI-BLAST L. tropica. They are closely related to Z32843.1 in Russia, at 99\%, as shown in Tables 6 and 7 and Figure 6.

Table 7: Type of polymorphism of Leishmania tropica of Lmj4 gene

\begin{tabular}{llllll}
\hline & Accession No. & Country & Source & Host & Compatibility (\%) \\
\hline 26. & Z32843.1 & Russia & Leishmania tropica & Homo sapiens & 99 \\
27. & MH51118.1 & Iraq: Kute & Leishmania tropica & Homo sapiens & 99 \\
\hline
\end{tabular}

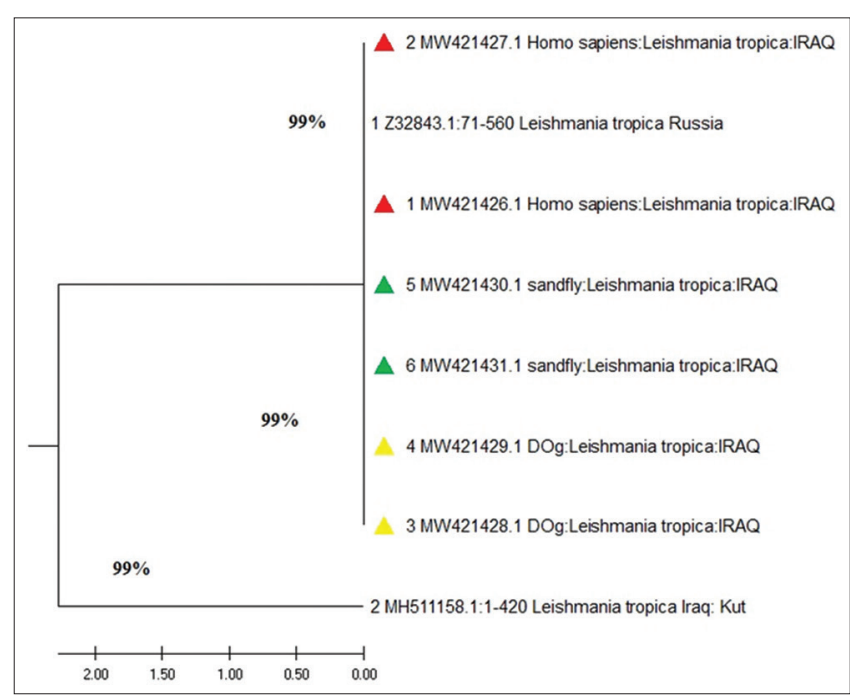

Figure 6: Neighbor-joining tree Leishmania tropica of Lmj4 gene. New sequences derived from this study are marked with green for sandflies, red for human, and yellow for dogs. The GenBank accession numbers, species of infected host, and country of origin are included for each sequence

\section{Discussion}

The genomic DNA from 100 skin biopsies from human, 237 dog samples (74 skin biopsies and 163 blood samples), and 147 samples of female sandfly tissues were extracted. DNA extraction and purification were successfully performed using Isolation Kit (MagPurix ${ }^{\circledR}$ Viral/Pathogen Nucleic Acids Extraction Kit A/Zinexts Life Science Corp./Taiwan).

Until now, the diagnosis of $\mathrm{CL}$ has been difficult in endemic regions where different species of Leishmania can present with very similar appearance and where different skin diseases with similar clinical symptoms occur. Both the gold standard parasitological techniques of the direct identification of amastigotes in microscopy samples and/or culture of promastigotes from infected tissues are highly specific but are not very sensitive [22]. Because of there are three different hosts (human, dogs, and sandflies) samples and to be more accurate as well as to reduce the effort, time, and cost. We contributed the diagnosis of CL spp. in combination particularly in Iraq and internationally in the Middle East countries by nested PCR, as the first study to our knowledge conducted in this way.

A search of the PubMed database revealed that, since 1989, more than 700 articles on PCR diagnosis of leishmaniases have been published, in which a multitude of gene targets, protocols, and applications have been described, including genus and/ or species-specific PCR, ranging from low-tech to hightech approaches [22].

We used the SSU (18S) rRNA gene to diagnose and confirm the diagnosis of leishmaniases in patients, their dogs, and sandflies caught from 
the patient's environment. The PCR-based assays remain the main molecular diagnostic methods for the diagnosis of Leishmania parasites in clinical samples [23]. PCR primers targeting the kinetoplast and ribosomal DNA genes are among the most frequently utilized for the detection and/or identification of Leishmania spp. in the Old World and they reveal perfect findings [24], [25], [26], [27], [28], [29].

The PCR showed the rate of CL infection in the patients was $100 \%$, and this is corresponding with the estimated CL infection rate using traditional and staining methods. These genes consider as an important virulent factor for Leishmania to make infection as reported by Mauricio et al. [30]. Mouttaki et al., Bensoussan et al., and Kumar et al. reported that LITSR/L5.8S and Lmj4/ Uni21 primers are highly sensitive, sometimes reaching $100 \%$ in identifying $C L$ by nested PCR and PCRRFLP [22], [28], [29].

Patients with $\mathrm{CL}$ in Al-Diwanyah Teaching Hospital were diagnosed by real-time PCR and showed that $89.09 \%$ of the samples were positive, while only $10.9 \%$ were negative [31].

The infection rate was $95.95 \%$ in dogs that showed clinical signs on their skin and $35.58 \%$ in asymptomatic dogs. This is compatible with what researcher found in Saudi Arabia, showed 31 (5.9\%) of 526 samples were positive for genus Leishmania. Two of 198 Riyadh dogs identified as infected with Leishmania spp., with 18 of 175 and 11 of 153 found positive in Al-Ahsa Oasis and Al-Qaseem by kDNA-PCR, respectively [32].

In this study, nested PCR of the SSU (18S) rRNA gene proved to be more sensitive for Leishmania species identification. This was consistent with several previous studies that used nestedPCR [33], [34], [35], [36], [37], [38], [39].

The difference in the ratios between this study and comparative studies may be that domestic dogs returning to infected patients were the target while stray dogs were the target in Saudi Arabia.

The rate of infection in engorged sandflies was $46.94 \%$, because the parasite does not stay long in the insect when the final host is present. This was indicated by a study revealed that 16 pools (100\%) were positive after PCR amplification, while none of the specimens were negative for the parasite [40]. Azizi et al., reported the natural infection of Phlebotomus papatasi with L. major in this endemic focus of ZCL by nested PCR [41]. Recently, molecular studies have shown that $P$. papatasi has a key role in $L$. major transmission by nested and real-time PCR [38], [42], [43].

The results of the molecular study were probably based on sampling location, primer and DNA extraction. The PCR procedure offers several advantages, including faster processing time, higher sensitivity, and decreased contamination risk, and seems to be a suitable tool for the direct diagnosis and characterization of Leishmania species compared with other methods reported by Seray et al. [44].

The nested PCR results showed that $88 \%$ of human and $95.77 \%$ of symptomatic dogs and $20.69 \%$ of asymptomatic dogs, and $40.58 \%$ of sandflies samples were positive for $L$. major. These high percentages of L. major, explained by its more prevalent in central and southern Iraq, and are represent the zoonotic type among the three hosts, while the rate of $L$. tropica infection was positive in $12 \%$ of human, in dogs the percent were $4.23 \%$ (symptomatic), and $6.89 \%$ (asymptomatic), and $27.54 \%$ of sandflies samples, and this similar to other studies in Al-Qadisiyah province [31]. The nested PCR method was used to determine the Leishmania parasite and its species, the results for positive samples showed that the proportion $95.91 \%$ were L. major and just $2 \%$ were L. tropica [31]. These findings, especially for human, are disagreement with [45], [46], who found L. tropica was the main species, comprising $88.5 \%$ of CL cases, while L. major was found in $11.5 \%$ of the detected cases in Kerman, Iran and they used nested PCR. These findings are also unlike the conclusions of many researchers used molecular methods of nested PCR in Yemen, who mentioned that $\mathrm{CL}$ is most commonly caused by $L$. tropica, suggesting anthroponotic transmission of CL [47].

Mohebali et al., supporting our results of secondary set of primers amplification by nested PCR, they concluded that domestic and wild canine infections with $L$. major may be more prevalent in areas of endemic human L. major CL than currently recognized, and canines should be evaluated as possible additional reservoirs for human infection [48]. Also, Solano-Gallego et al., studied different clinical and parasitological findings in canine $L$. major and $L$. tropica infections and indicated that PCR with DNA sequencing of the affected tissues or blood should be used in dogs to discriminate between infections with these three Old World Leishmania spp. [49].

Bamorovat et al., found L. tropica infection was more prevalent in stray dogs in Iran by PCR amplification of kDNA, which is different from our findings [50].

Abdulwahab, reported that from 55 positive samples, 33 samples were identified as L. major $(60 \%)$ with amplicon molecular weighted $430 \mathrm{bp}$, and 22 samples were identified as L. tropica [51].

Other studies in nearby countries, such as Iran Saki et al. documented that the high frequency of $L$. major may be due to the presence of large numbers of reservoir animals, especially rodents and dogs (reservoir of L. major) by used RFLP-PCR [52]. Obviously, dense populations of natural hosts of L. major, together with abundant vector sandflies, are the key elements responsible for the high rate of human infection [52].

The prevalence of Leishmania species infecting stray dogs in Saudi Arabia was 4.0\% L. major and 1.9\% 
L. tropica [32]. This variation in the rate of infection in dogs is due to the fact that the dogs targeted in this study are owned-dogs for patients with CL, whereas the target dogs in Saudi Arabia were stray dogs, as well as the use of different special primers, in addition to the sensitivity, which have a fundamental role in the appearance of the results more accurate and clear [32].

In the last two decades, PCR-based procedures targeting different genes have been successfully used to directly detect and characterize Leishmania spp. in clinical specimens and used for taxonomic, epidemiologic, population genetic, and phylogenetic analyses. In addition, the refined features of a gene are carried out by sequencing for spatial distribution and molecular identification [20], [53], [54].

However, Leishmania species are associated with certain clinical features of the disease, and the parasite identification should not be diminished at species level detections, for that reasons typing techniques are required. The nucleotide sequencing analysis process is a popular and effective method for Leishmania species typing [53]. This kind of data can help in solution strain heterogeneity link to geographical origin, and this technique has the benefit of identifying genetic variability directly from samples without having to culture the causative organism [55].

The phylogenetic tree of this study showed more heterogeneity in $L$. major compared with L. tropica, possibly due to circulation of different clones within the study area in Misan province. This finding is in disagreement with [45].

The phylogenetic analysis of Iraqi strains of local L. major organisms in human samples is closely related to those from Jordan, Turkey: Sanliurfa, Iraq (Sulaimani), Iran, Thailand, Iran (Mashhad), Belgium, India (West Bengal), UK, USA, Germany, Kenya, Austria, and Sudan at $99 \%$. The phylogenetic analysis of dog strains of the local L. major samples shows they are closely related to strains from Iran, Mediterranean Sea at $99 \%$. Regarding sandfly sequences, those of the local $L$. major are closely related to those from Iran, Ilam province, at $99 \%$, and with West Bank and Iran at $98 \%$.

In human, the sequences of the local L. tropica samples are closely related to those from Russia and Iraq (Kute) at 99\%. Among dogs, the sequences are closely related to those from Russia, at $99 \%$. In sandflies, the sequences are closely related to those from Russia at $99 \%$.

These variations may be due to multifactorial reasons and patients factors, for example, patients' immunity, medication, habits, lifestyle, social factors, and economic factors, or may be due to environmental reasons such as a region's demography, climate factors, and change in metrological factors. There may also be factors related to human such as migrations from rural to urban areas, traveling to endemic areas, and use of insecticides. Genotyping at the species level is essential for monitoring the relative frequency of $C L$ in the Iraq area that is correlated to two different Leishmania species ( $L$. major and $L$. tropica), each characterized by distinct epidemiological features. The obtained results highlight the need to find a universally accepted diagnostic tool for Leishmania typing [31].

Many observations have led to the hypothesis that Leishmania spp. rapidly adapts to individual hosts, sparking intensive research into the underlying mechanisms of genetic variation [56]. Isolation in Iraqi showed the similarity with the strains of the Western type as the role of human migration may be ruled out since $L$. tropica and $L$. major seemed to have been spread in Africa and Middle East, besides European colonial expansion for 500 years [56], [57]. Most probably, strains from the Middle East arrived in Europe and took the Western type as its genotype [58].

Finally, genomic detection not only has a role in the diagnosis of Leishmania species responsible for disease but also for the postulation of targeted therapies, management, favorable identification, effective control measures and prevention strategies, and the study of the epidemiology and dynamics of the disease.

\section{Conclusion}

To our knowledge, this is the first study that contributes to a diagnosis of CL spp. in combination with three hosts (human, dogs, and sandflies), particularly in Iraq and generally in Middle East countries by nested PCR. Nested-PCR has high sensitivity, specificity, and accuracy powerful, and is a perfect approach for the identification of Leishmania species extracted from clinical samples (i.e., aspiration fluids and culturing specimens). The phylogenetic nucleotides sequencing analyses targeting SSU (18S) rRNA gene are valuable tools in genetic analytical characterization and management of CL patients where the disease is highly endemic. In addition, the study indicated that L. major has a high degree of intraspecific diversity relatively over the diversity of Leishmania tropica.

\section{Authors' Contribution}

Study design: ARKA, KMH. Main manuscript preparation: ARKA. An important revision of the manuscript: ARKA. All authors read and approved the final manuscript. 


\section{Acknowledgments}

The authors would like to thank Dr. Ahmed Salih for their helping.

\section{References}

1. Centers for Disease Control and Prevention. Update CL in US military personnel. Southwest Central Asia, 2011-2012. MMWR Morb Mortal Wkly Rep. 2012;53(12):264-5.

PMid:15057192

2. Hepburn NC. Cutaneous leishmaniasis: An overview. J Postgrad Med. 2003;49(1):50-4.

PMid:12865571

3. Markle WH, Makhoul K. Cutaneous Leishmaniasis Recognition and Treatment. Am Fam Physician. 2004;69(6):1455-60. PMid: 15053410

4. Mandell GL, Bennett JE, Dolin R. In: Mandell D, Bennett JE, editors. Principles and Practice of Infectious Diseases. $6^{\text {th }}$ ed Amsterdam, Netherlands: Elsevier; 2005. p. 2428-42. https:// doi.org/10.1086/655696

5. Kumar A, Samant M. DNA vaccine against visceral leishmaniasis: A promising approach for prevention and control. Parasite Immunol. 2016;38(5):273-81. https://doi.org/10.1111/ pim. 12315

PMid:27009772

6. Filho JD, Brazil RP. Relationships of new world phlebotomine sand flies (Diptera: Psychodidae) based on fossil evidence. Mem Inst Oswaldo Cruz. 2003;98(Suppl 1):145-9. https://doi. org/10.1590/s0074-02762003000900022

PMid:12687775

7. González U, Pinart M, Reveiz L, Alvar J. Interventions for old world cutaneous leishmaniasis. Cochrane Database Syst Rev. 2008;4:CD005067. https://doi.org/10.1002/14651858. cd005067.pub3

PMid: 18843677

8. World Health Organization. Global Leishmaniasis Surveillance, 2017-2018, and First Report on 5 Additional Indicators. Geneva: World Health Organization; 2018.

9. Al-Samarai AM, Al-Obaidi HS. Cutaneous leishmaniasis in Iraq. J Infect Dev Ctries. 2009;3(2):123-9.

PMid: 19755742

10. Habeeb MA. A Systematic, Ecological and Microbial Studies of the Sandflies (Diptera: Psychodidae; Phlebotominae) in Basrah Governorate, Iraq. Basrah: Thesis The University of Basrah; 2005. https://doi.org/10.21276/ijaq.2013.10.1.5

11. Dantas-Torres $F$, de Brito ME, Brandão-Filho SP. Seroepidemiological survey on canine leishmaniasis among dogs from an urban area of Brazil. Vet Parasitol. 2006;140(1-2):5460. https://doi.org/10.1016/j.vetpar.2006.03.008 PMid:16621286

12. Elbihari S, Kawasmeh ZA, Al Naiem AH. Possible reservoir host(s) of zoonotic cutaneous leishmaniasis in Al-Hassa oasis, Saudi Arabia. Ann Trop Med Parasitol. 1984;78(5):543-5. https:// doi.org/10.1080/00034983.1984.11811861

PMid:6395818

13. Bamorovat M, Sharifi I, Aflatoonian MR, Sharifi $H$, Karamoozian A, Sharifi F, et al. Risk factors for anthroponotic cutaneous leishmaniasis in unresponsive and responsive patients in a major focus, Southeast of Iran. PLoS One. 2018;13(2):e0192236. https://doi.org/10.1371/journal. pone.0192236

PMid:29415078

14. Bañuls $\mathrm{AL}$, Hide $\mathrm{M}$, Prugnolle $\mathrm{F}$. Leishmania and the leishmaniases: A parasite genetic update and advances in taxonomy, epidemiology, and pathogenicity in human. Adv Parasitol. 2007;64:1-458. https://doi.org/10.1016/ s0065-308x(06)64001-3

PMid: 17499100

15. Yehia L, Adib-Houreih M, Raslan WF, Kibbi AG, Loya A Firooz A, et al. Molecular diagnosis of cutaneous leishmaniasis and species identification: Analysis of 122 biopsies with varied parasite index. J Cutan Pathol. 2012;39(3):347-55. https://doi. org/10.1111/j.1600-0560.2011.01861.x

PMid:22335594

16. Parvizi $P$, Ready PD. Nested PCRs and sequencing of nuclear ITS-rDNA fragments detect three Leishmania species of gerbils in sandflies from Iranian foci of zoonotic cutaneous leishmaniasis. Trop Med Int Health. 2008;13(9):1159-71. https:// doi.org/10.1111/j.1365-3156.2008.02121.x

PMid: 18631311

17. Montalvo AM, Fraga J, Monzote L, Montano I, De Doncker S, Dujardin JC, et al. Heat-shock protein 70 PCR-RFLP: A universal simple tool for Leishmania species discrimination in the new and old world. Parasitology. 2010;137(8):1159-68. https://doi. org/10.1017/s0031182010000089

PMid:20441679

18. Da Silva LA, de Sousa CS, da Graca GC, Porrozzi R, Cupolillo E. Sequence analysis and PCR-RFLP profiling of the hsp70 gene as a valuable tool for identifying Leishmania species associated with human leishmaniasis in Brazil. Infect Genet Evol. 2010;10(1):77-83. https://doi.org/10.1016/j. meegid.2009.11.001

PMid:19913112

19. Sambrook J, Russell D. Molecular Cloning: A Laboratory Manual. $3^{\text {rd }}$ ed. Cold Spring Harbor: Cold Spring Harbor Laboratory Press; 2001. https://doi.org/10.5962/bhl.title.49161

20. Akhoundi M, Kuhls K, Cannet A, Votýpka J, Marty P, Delaunay P, et al. A historical overview of the classification, evolution, and dispersion of Leishmania parasites and sandflies. PLoS Negl Trop Dis. 2016;10(3):e0004349. https://doi.org/10.1371/journal. pntd.0004349

PMid:26937644

21. Van der Auwera G, Ravel C, Verweij JJ, Bart A, Schönian G, Felger I. Evaluation of foursingle-locus markers for Leishmania species discrimination by sequencing. J Clin Microbiol. 2014;52(4):1098-104. https://doi.org/10.1128/jcm.02936-13 PMid:24452158

22. Mouttaki T, Morales-Yuste M, Merino-Espinosa G, Chiheb $S$, Fellah H, Martin-Sanchez J, et al. Molecular diagnosis of cutaneous leishmaniasis and identification of the causative Leishmania species in Morocco by using three PCR-based assays. Parasites Vectors. 2014;7:420. https://doi.org/10.1186/1756-3305-7-420

23. Reithinger R, Dujardin JC. Molecular diagnosis of leishmaniasis: Current status and future applications. J Clin Microbiol 2007;45(1):21-5. https://doi.org/10.1128/jcm.02029-06 PMid: 17093038

24. El-Beshbishy HA, Al-Ali KH, El-Badry AA. Molecular characterization of cutaneous leishmaniasis in Al-Madinah Al-Munawarah Province, Western Saudi Arabia. Int J Infect Dis. 2013;17(5):e334-8. https://doi.org/10.1016/j.ijid.2012.11.015 PMid:23253909

25. Azizi K, Soltani A, Alipour H. Molecular detection of Leishmania isolated from cutaneous leishmaniasis patients in Jask 
County, Hormozgan Province, Southern Iran, 2008. Asian Pac J Trop Med 2012;5(7):514-7. https://doi.org/10.1016/ s1995-7645(12)60090-x

\section{PMid:22647811}

26. Khademvatan S, Saki J, Maraghi S. Comparison of traditional methods and PCR for diagnosis of cutaneous leishmaniasis in South-West of Iran. Zahedan J Res Med Sci. 2012;14(8):1-5. PMid:22347259

27. Azmi K, Nasereddin A, Ereqat S, Schnur L, Schonian G Abdeen $Z$. Methods incorporating a polymerase chain reaction and restriction fragment length polymorphism and their use as a gold standard in diagnosing Old World cutaneous leishmaniasis. Diagn Microbiol Infect Dis. 2011;71(2):151-5. https://doi. org/10.1016/j.diagmicrobio.2011.06.004 PMid:21840670

28. Kumar R, Bumb RA, Ansari NA, Mehta RD, Salotra P. Cutaneous leishmaniasis caused by Leishmania tropica in Bikaner, India: Parasite identification and characterization using molecular and immunologic tools. Am J Trop Med Hyg 2007;76(5):896-901. https://doi.org/10.4269/ajtmh.2007.76.896 PMid:17488912

29. Bensoussan E, Nasereddin A, Jonas F, Schnur LF, Jaffe $\mathrm{CL}$. Comparison of PCR assays for diagnosis of cutaneous leishmaniasis. J Clin Microbiol. 2006;44(4):1435-9. https://doi. org/10.1128/jcm.44.4.1435-1439.2006

PMid:16597873

30. Mauricio I, Stothard A, Miles M. Leishmania donovani complex: Genotyping with the ribosomal internal transcribed spacer and the mini-exon. Parasitology. 2004;128(3):263-7. https://doi. org/10.1017/s0031182003004578 PMid:15074875

31. Aldifaei RS. Prevalence of Cutaneous Leishmaniasis in AL-Qadissia Province and the Evaluation of Treatment Response by Pentostam with RT-PCR, Thesis; 2013.

32. Alanazi AD, Puschendorf $R$, Alyousif MS, Al-Khalifa MS, Alharbi SA, Al-Shehri ZS, et al. Molecular detection of Leishmania spp. in skin and blood of stray dogs from endemic areas of cutaneous leishmaniasis in Saudi Arabia. Iran J Parasitol. 2019;14(2):231-9. https://doi.org/10.18502/ijpa.v14i2.1135 PMid:31543911

33. Ajouad M, Es-Sette N, Hamdi S, El-Idrissi A, Riyad M Lemrani M. Detection and molecular typing of Leishmania tropica from Phlebotomus sergenti and lesions of cutaneous leishmaniasis in an emerging focus of Morocco. Parasit Vectors. 2013;6(1):217. https://doi.org/10.1186/1756-3305-6-217 PMid:23890256

34. El Tai NO, EI Fari M, Mauricio I, Miles MA, Oskam L, El Safi SH, et al. Leishmania donovani: Intraspecific polymorphisms of Sudanese isolates revealed by PCR-based analyses and DNA sequencing. Exp Parasitol. 2001;97(1):35-44. https://doi. org/10.1006/expr.2001.4592

PMid:11207112

35. El Tai NO, Osman OF, El Fari M, Presber W, Schönian G. Genetic heterogeneity of ribosomal internal transcribed spacer in clinical samples of Leishmania donovani spotted on filter paper as revealed by single-strand conformation polymorphisms and sequencing. Trans R Soc Trop Med Hyg. 2000;94(5):575-9. https://doi.org/10.1016/s0035-9203(00)90093-2 PMid:11132393

36. Spanakos G, Piperaki ET, Menounos PG, Tegos N, Flemetakis A, Vakalis NC. Detection and species identification of old world Leishmania in clinical samples using a PCR based method. Trans R Soc Trop Med Hyg. 2008;102(1):46-53. https://doi. org/10.1016/j.trstmh.2007.05.019

PMid:17669452
37. Schallig HD, Oskam L. Molecular biological applications in the diagnosis and control of leishmaniasis and parasite identification. Trop Med Int Health. 2002;7(8):641. https://doi. org/10.1046/j.1365-3156.2002.00911.x PMid:12167091

38. Parvizi P, Moradi G, Akbari G, Farahmand M, Ready PD, Piazak N, et al. PCR detection and sequencing of parasite ITS-rDNA gene from reservoir host of zoonotic cutaneous leishmaniasis in central Iran. Parasitol Res. 2008;136(6):128995. https://doi.org/10.1007/s00436-008-1220-0 PMid:18791741

39. Es-Sette N, Ajaoud M, Bichaud L, Hamdi S, Mellouki F, Charre $\mathrm{RN}$, et al. Phlebotomus sergenti a common vector of Leishmania tropica and Toscana virus in Morocco. J Vector Borne Dis. 2014;51(2):86-90. https://doi.org/10.1186/s13071-015-0826-1 PMid:24947214

40. Al-Huchaimi S, Al-Nafakh R, Al-Khafaji Z, Amad N, Mahmood T, Bedri S, et al. Phylogenetic analysis of sandflies populations using cytochrome b (mtCytb) gene and identification of Leishmania DNA within infected sandflies, from the city of Najaf, Iraq. J Contemp Med Sci. 2018;4(3):163-9.

41. Azizi K, Badzohreh A, Sarkari B, Fakoorziba MR, Kalantari M, Moemenbellah-Fard MD, et al. Nested polymerase chain reaction and sequence-based detection of Leishmania infection of sand flies in recently emerged endemic focus of zoonotic cutaneous leishmaniasis, Southern Iran. Iran J Med Sci. 2013;38(Suppl 2):156-62. https://doi.org/10.1089/ vbz.2011.0872

PMid:24031105

42. Azizi K, Rassi Y, Moemenbellah-Fard MD. PCR-based detection of Leishmania major kDNA within naturally infected Phlebotomus papatasi in Southern Iran. Trans R Soc Trop Med Hyg. 2010;104(6):440-2. https://doi.org/10.1016/j. trstmh.2010.01.008

PMid:20129635

43. Davami MH, Motazedian MH, Kalantari M, Asgari Q, Badzohre A Mohammadpour I. First microscopical and molecular-based characterization of Leishmania major within naturally infected Phlebotomus salehi (Diptera; Psychodidae) in Fars Province, Southern Iran. Ann Trop Med Parasitol. 2011;105(7):485-91. https://doi.org/10.1016/s1201-9712(11)60330-5 PMid:22185942

44. Seray O, Toz G, Fadile Y, Hatice E, Ziya A, Aslı V, et al. A realtime ITS1-PCR based method in the diagnosis and species identification of Leishmania parasite from human and dog clinical samples in Turkey. PLoS Negl Trop Dis. 2013;7(5):e2205. https://doi.org/10.1371/journal.pntd.0002205 PMid:23675543

45. Ramezany M, Sharifi I, Babaei Z, Almani PG, Heshmatkhah A Keyhani A, et al. Geographical distribution and molecular characterization for cutaneous leishmaniasis species by sequencing and phylogenetic analyses of kDNA and ITS1 loci markers in South-Eastern Iran. Pathog Glob Health. 2018;112(3):132-41. https://doi.org/10.1080/20477724.2018.14 47836

PMid:29536818

46. Sharifi F, Sharifi I, Zarean M, Parizi MH, Aflatoonian M, Harandi MF, et al. Spatial distribution and molecular identification of Leishmania species from endemic foci of south-eastern Iran. Iran J Parasitol. 2012;7(1):45-52.

PMid:23133471

47. Mahdy MA, Al-Mekhlafi HM, Al-Mekhlafi AM, Lim YA, Bin Shuaib NO, Azazy AA, et al. Molecular characterization of Leishmania species isolated from cutaneous leishmaniasis in Yemen. PLoS One. 2010;5(9):e12879. https://doi.org/10.1371/ journal.pone.0012879 


\section{PMid:20862227}

48. Mohebali M, Malmasi A, Hajjaran H, Jamshidi S, Akhoundi B Rezaei $\mathrm{M}$, et al. Disseminated leishmaniasis caused by Leishmania tropica in a puppy from Karaj, Central Iran. Iran J Parasitol. 2011;6(2):69-73.

PMid:22347291

49. Solano-Gallego L, Miró G, Koutinas A, Cardoso L, Pennisi MG, Ferrer $\mathrm{L}$, et al. LeishVet guidelines for the practical management of canine leishmaniosis. Parasit Vectors. 2011;4:86. https://doi. org/10.1186/1756-3305-4-86

PMid:21599936

50. Bamorovat M, Sharifi I, Dabiri S, Mohammadi MA, Harandi MF, Mohebali M, et al. Leishmania tropica in Stray Dogs in Southeast Iran. Iran J Public Health. 2015;44(10):1359-66. PMid:26576349

51. Abdulwahab AR. Genotype of Cutaneous Leishmaniasis in Iraq in Correlation with Dental Broach Smear and Histopathological Section. Baghdad: Thesis College of Medicine, University of Baghdad; 2013.

52. Saki J, Meamar A, Oormazdi H, Akhlaghi L, Maraghi $S$, Mohebali M, et al. Mini-exon genotyping of Leishmania species in Khuzestan Province, Southwest Iran. Iran J Parasitol. 2010;5(1):25-34. https://doi.org/10.5812/jjm.4805 PMid:22347232

53. Van der Auwera G, Dujardin JC. Species typing in dermal leishmaniasis. Clin Microbiol Rev. 2015;28(2):265-94. https:// doi.org/10.1128/cmr.00104-14

\section{PMid:25672782}

54. Bamorovat M, Sharifi I, Mohammadi MA, Eybpoosh S, Nasibi S, Aflatoonian MR, et al. Leishmania tropica isolates from nonhealed and healed patients in Iran: A molecular typing and phylogenetic analysis. Microb Pathog. 2018;116:124-9. https:// doi.org/10.1016/j.micpath.2018.01.021 PMid:29353004

55. Schonian G, Schnur L, El Fari M, Oskam L, Kolesnikov AA, Sokolowska-Köhler W, et al. Genetic heterogeneity in the species Leishmania tropica revealed by different PCR-based methods. Trans R Soc Trop Med Hyg. 2001;95(2):217-24. https://doi.org/10.1016/s0035-9203(01)90173-7

56. Ekşi F, Özgöztaşı O, Karslıgil T, Sağlam M. Genotyping Leishmania promastigotes isolated from patients with cutaneous leishmaniasis in South-Eastern Turkey. J Int Med Res 2017;45(1):114-22. https://doi.org/10.1177/0300060516677155.

57. Salloum T, Khalifeh I, Tokajian S. Detection, molecular typing and phylogenetic analysis of Leishmania isolated from cases of leishmaniasis among Syrian refugees in Lebanon. Parasite Epidemiol Control. 2016;1(2):159-68. https://doi.org/10.1016/j. parepi.2016.02.002

58. Parvizi P, Baghban N, Novin EA, Absavaran A. Detection, identification and molecular typing of Leishmania major in Phlebotomus papatasi from a focus of zoonotic cutaneous leishmaniasis in central of Iran. Exp Parasitol. 2010;124(2):232-7. https://doi.org/10.1016/j.exppara.2009.10.004

PMid:19854172 